\title{
La agricultura mexicana y el mercado japonés: oportunidades y retos para México
}

DOI: $10.32870 /$ mycp.v8i26.266

Hiroyuki Tani*

\section{Introducción}

L as exportaciones mexicanas de hortalizas y frutas han aumentado mucho desde la segunda mitad de los años noventa. En el mercado norteamericano México es uno de los proveedores más importantes en esta área, porque ha aprovechado sus ventajas comparativas: clima templado, cercanía geográfica e institucional y abundante mano de obra barata, entre otras. Sin embargo, lo anterior no puede prolongarse indefinidamente, por eso México debe seguir trabajando ante sus nuevos desafíos.

Hoy en día el país avanza en el proceso de ratificación del tratado de libre comercio entre Estados Unidos, los cinco países centroamericanos y la República Dominicana, el cual se conoce como CAFTA-DR (por sus siglas en inglés). Este liberalizará no solamente los flujos de bienes y servicios entre dichos países, sino también allanará el terreno centroamericano para las inversiones norteamericanas como hizo el TLCAN en México. Una vez que entre en vigor dicho tratado, es posible que a México le aparezcan rivales — pequeños pero fuertes- ubicándose más al sur y una mano de obra todavía más barata.

* Profesor asociado del Departamento de Estudios Hispánicos, Universidad Sofía, Tokio, Japón. De abril de 2005 a marzo de 2006, investigador visitante del Departamento de Estudios del Pacífico, Universidad de Guadalajara.
Habrá varias alternativas para enfrentar este nuevo reto: reducir todavía más los costos de producción, inventar nuevas demandas internas, buscar más valores agregados con la diversificación no sólo de sus productos, sino también de sus mercados, por ejemplo. Todas estas opciones, en mayor o menor medida, servirán para fortalecer la competitividad del sector hortofrutícola mexicano.

Este artículo se enfoca al aspecto de la diversificación de mercados. La gran mayoría de las exportaciones mexicanas se dirige al vecino del Norte. Este hecho indica que México siempre puede contar con un mercado bien asegurado, pero al mismo tiempo es un riesgo bastante grande depender de un solo país y Japón podría ser una excelente alternativa.

El trabajo se compone de las partes siguientes. El primer apartado estudia el comportamiento de las exportaciones hortofrutícolas de México. El siguiente examina las características de las importaciones japonesas de productos mexicanos en los últimos tres lustros, a la luz de las estadísticas del comercio exterior de Japón compiladas por su Ministerio de Finanzas. ${ }^{1}$ Veremos que las importaciones hortícolas están totalmente estancadas, aunque las de frutas son más prometedoras. Esto no significa que Japón haya dejado de importar masivamente las verduras. Al contrario, ha aumentado mucho sus importaciones: los consumidores japoneses compran millones 


\section{Análisis}

de toneladas de hortalizas importadas. En el tercer apartado veremos que este mercado lo ha conseguido China y en el cuarto consideraremos la factibilidad de que México entre en el mercado japonés. La respuesta que encontramos es negativa si seguimos el ejemplo de China. En el último apartado exploramos algunas opciones para que los productos agrícolas mexicanos logren una mayor presencia en el mercado japonés basándonos en las recientes transformaciones de la sociedad japonesa.

\section{Las exportaciones hortofrutícolas de México: el comportamiento reciente}

México está localizado al sur de Estados Unidos, tiene un clima templado, mano de obra barata y es un gran exportador tradicional de productos agrícolas al vecino país del Norte. Sin embargo, como mencionamos líneas arriba, las exportaciones mexicanas han aumentado notoriamente desde la segunda mitad de los años noventa. La gráfica 1 muestra el rápido aumento de las exportaciones de los principales productos hortofrutícolas de México, resultado de la liberalización del comercio y la inversión del TLCAN, aunado a la masiva devaluación del peso en los años 1994 y 1995. Por esa razón los consumidores norteamericanos compraron verduras y frutas baratas, y tuvieron la oportunidad de disfrutar de una dieta más sana. A su vez, México obtuvo más empleos y más divisas.

Sin embargo, aunque el mercado norteamericano sea grande, habrá un cierto punto de saturación posterior. Además, la competencia puede hacerse más severa día a día, dado que Estados Unidos ya cuenta con el tratado de libre comercio con Chile, que también es un país exportador de productos agrícolas de gran fama, y está a punto de ratificar otro con los países cen-

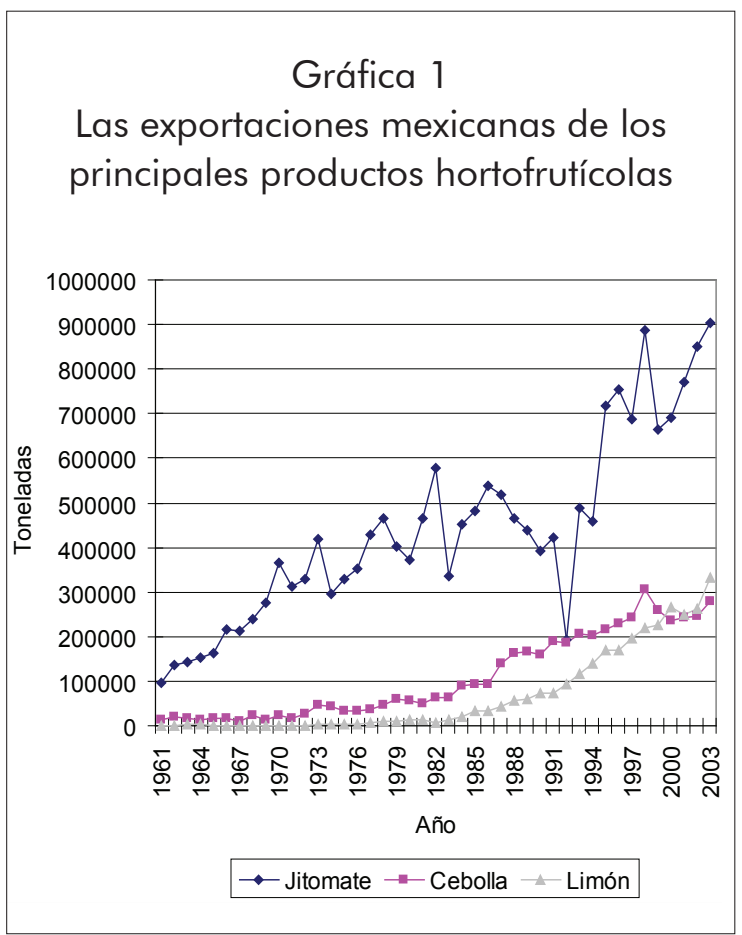

troamericanos - Guatemala es ya uno de los proveedores principales de hortalizas baratas-. Como el tratado incluye la liberación de las inversiones estadounidenses, es posible que aumenten las agromaquilas en la región. Por lo tanto, México debería diversificar más su mercado.

\section{Las importaciones japonesas de productos agrícolas de México}

Hoy no sabemos con exactitud si los productos hortofrutícolas mexicanos han entrado en el mercado japonés, el cual, junto con el de la Unión Europea, es uno de los más provechosos del mundo. Japón cuenta con una población de más de 120 millones de habitantes y su producto interno bruto (РIB) es aproximadamente el doble del total latinoamericano. ${ }^{2}$ Es potencialmente grande, pero los productores mexicanos todavía no lo han explotado bien.

La tabla 1 muestra las importaciones japonesas de productos hortofrutícolas 
mexicanos en 2004. México ocupó el séptimo lugar en las importaciones de hortalizas frescas y refrigeradas con 3,368 millones de yenes (MDY). ${ }^{3} \mathrm{Su}$ participación en las importaciones totales fue de $3.5 \%$. En el área de las hortalizas congeladas, México se ubicó en el décimo lugar con un monto de 672 MDY y una escasa participación de $0.7 \%$. Las frutas se ven más prometedoras para los productores de México: se sitúa en el cuarto lugar en el mercado japonés con una venta de 11,922 MDY y su participación es de $5.2 \%$.

Tabla 1

Importación japonesa de productos hortofrutícolas mexicanas en 2004

\begin{tabular}{lccr}
\hline & $\begin{array}{c}\text { Hortalizas } \\
\text { frescas } \\
\text { y refrigeradas }\end{array}$ & $\begin{array}{c}\text { Hortalizas } \\
\text { congeladas }\end{array}$ & Frutas \\
\hline $\begin{array}{l}\text { Lugar } \\
\text { Valor } \\
\text { (millones de } \\
\text { yenes) }\end{array}$ & 3,368 & 100. & 40. \\
$\begin{array}{l}\text { Participación } \\
(\%)\end{array}$ & 3.5 & 0.7 & 11,922 \\
\hline
\end{tabular}

Fuente: Ministerio de Finanzas de Japón.
La gráfica 2 enfatiza que las importaciones de hortalizas frescas y refrigeradas mexicanas se han estancado desde 1988. El caso de las hortalizas congeladas es más desastroso: aunque registraron un aumento notorio en la primera mitad de los años noventa, su auge desapareció abruptamente tras haber alcanzado 3,000 MDY en 1998. Por el contrario, las frutas registraron un incremento sin grandes altibajos. Lo anterior carece de importancia cuando se compara con las exportaciones mexicanas al mercado norteamericano.

Los productores mexicanos no han explotado el mercado nipón parcialmente debido a la protección del gobierno japonés, un sistema de distribución sumamente cerrado, además de la manera peculiar que tienen los japoneses de hacer negocios. Hasta cierto punto las razones anteriores son válidas. Sin embargo, falta agregar un punto importante: el conocimiento de las características de la demanda de los consumidores japoneses. Aunque el hecho de que las ventas mexicanas tengan éxito

\section{Gráfica 2}

Las importaciones japonesas de los productos hortofrutícolas mexicanos

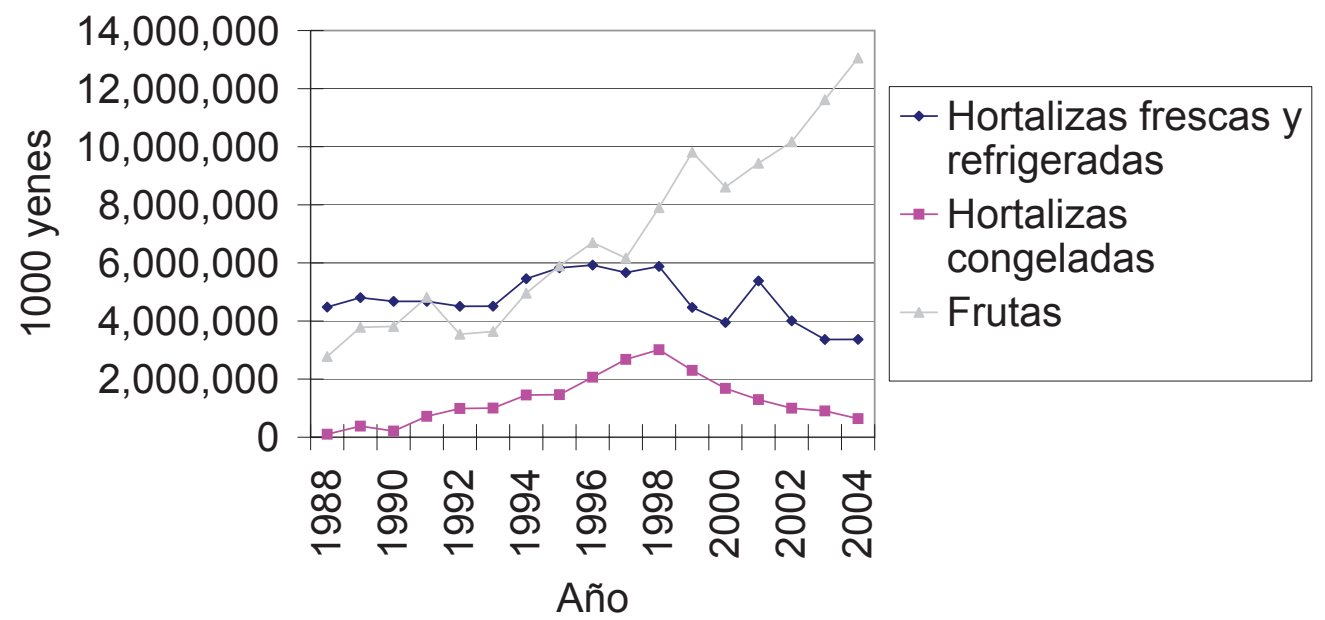


en Estados Unidos puede tener gran repercusión en Japón - por ejemplo, la cerveza Corona se vendió masivamente en Japón porque se puso de moda entre los jóvenes estadounidenses -, eso no significa que el mercado japonés sea una extensión —o "sucursal" - del mercado estadounidense.

Para conocer los productos mexicanos que más se han vendido en Japón, los desglosamos en géneros particulares. En la gráfica 3 observamos que su comportamiento fue estable en los últimos 15 años, excepto por un leve aumento de 1995 a 1998. Por otro lado, las exportaciones de México están poco diversificadas. En 2004 el 98.6\% del total de las importaciones japonesas de hortalizas mexicanas estaban compuestas por espárragos y calabaza cabocha. La gráfica 4 muestra un comportamiento semejante en el caso de las hortalizas congeladas, con el brócoli como prácticamente el único producto.

Por lo tanto, las exportaciones mexicanas aún satisfacen la demanda convencional. Por ejemplo, la calabaza cabocha es fuertemente demandada en invierno - so- bre todo en diciembre- porque se puede conservar durante mucho tiempo. Muchos japoneses consumen este tipo de calabazas en el solsticio de invierno. El producto podría ser importado si el costo de producción interna y el del inventario fueran más altos que la producción extranjera incluyendo el transporte. Sin embargo, como el producto era de demanda convencional y la elasticidad de la demanda en cuanto al precio y el ingreso era baja, las exportaciones no podían aumentar más allá de cierto punto. También hay mucha competencia en el verano, debido a la producción nacional, y en las demás estaciones a causa de las importaciones de Nueva Zelanda y Tonga, principalmente.

$\mathrm{El}$ caso de las frutas ratifica este argumento (gráfica 5). Como se puede ver en la gráfica anterior, las exportaciones de este sector crecieron vigorosamente, en particular las del aguacate. La gráfica 5 también indica que, junto con el aguacate, entraron al mercado japonés melón, limón y mango. El rubro de "otros" incluye muchos productos que México comenzó a exportar recien-

\section{Gráfica 3}

Las importaciones japonesas de hortalizas frescas y refrigeradas mexicanas

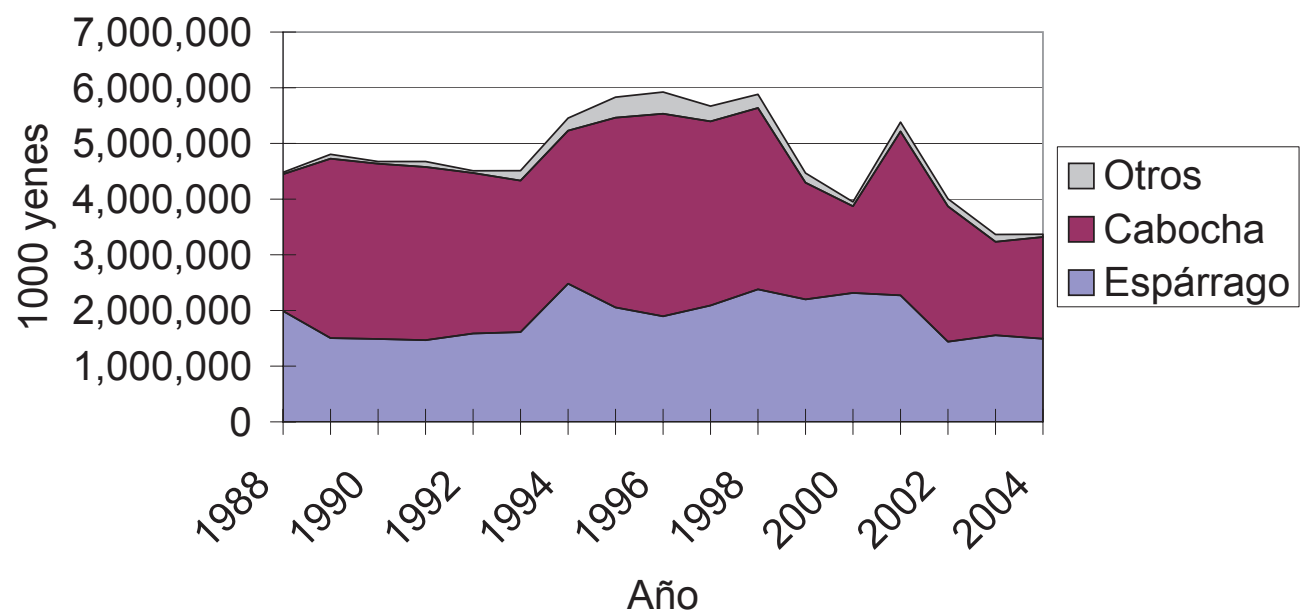



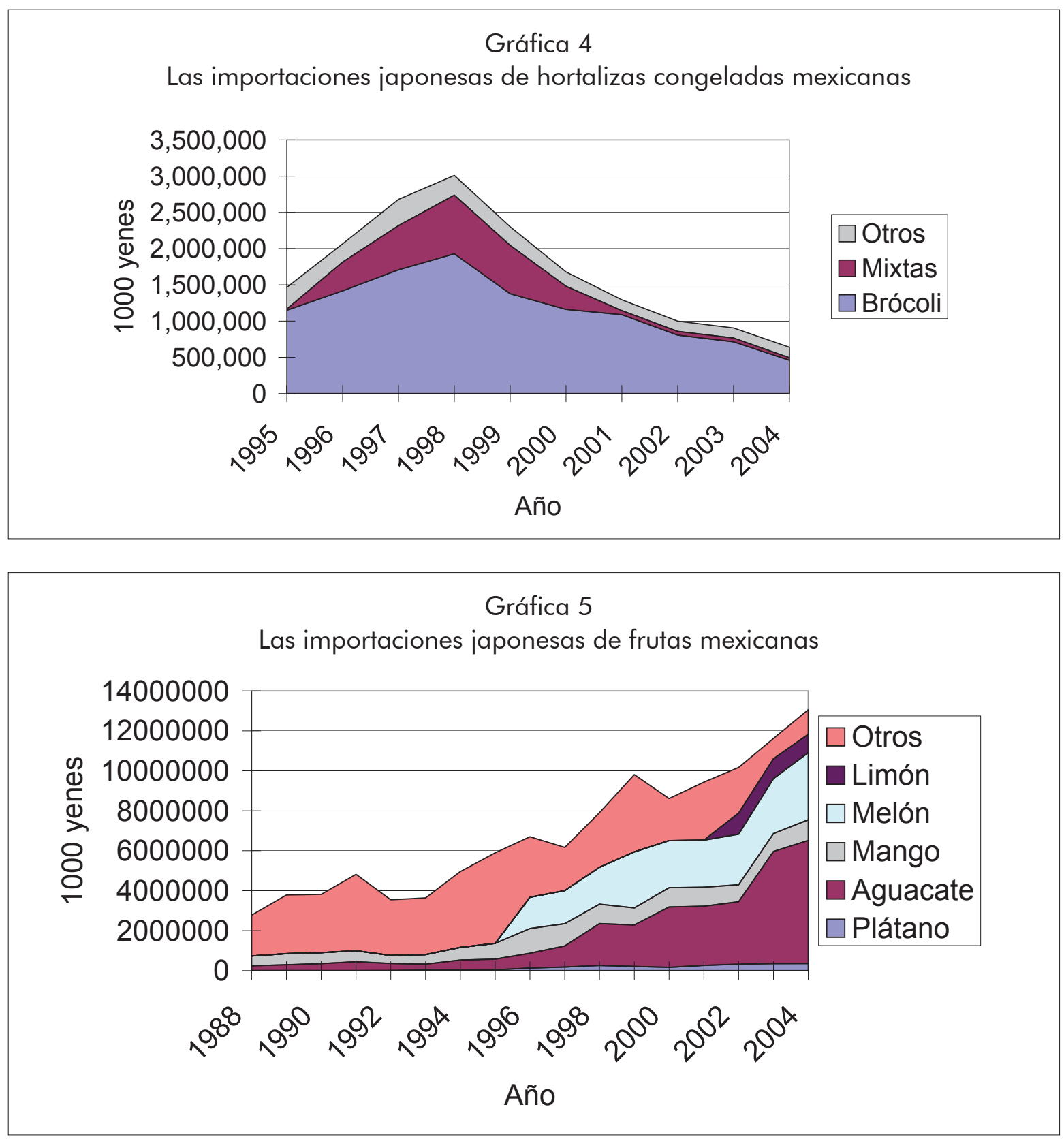

temente. Anteriormente, los melones que consumían los japoneses eran producción nacional. Había dos clases de melones: "con red" y "sin red" en la superficie del fruto ("musk melon" y "prince melon", respectivamente). Como los primeros son de lujo su demanda era prácticamente para regalos especiales. A los compradores no les importa su precio. De hecho, este alto precio representa el prestigio del regalo. Por el contrario, los otros melones son para el consumo popular y cotidiano. Por esa razón los melones cantaloupe importados abrieron un nuevo mercado: son melones "con red" pero más baratos.

De la misma manera, antes los únicos limones que conocían los consumidores japoneses eran los amarillos importados 
de Estados Unidos. Los limones mexicanos recién importados descubrieron nuevos gustos entre los paladares japoneses, especialmente entre las generaciones jóvenes. Lo mismo puede decirse del aguacate y el mango. Hace diez años eran productos netamente exóticos, tal vez suntuarios, que sólo unos cuantos consumidores disfrutaban en gurmés —o los que habían visitado México-. Ahora los japoneses están más familiarizados con estos productos tropicales y empiezan a consumirlos a su manera. Muchos japoneses saborean los aguacates con salsa de soya y wasabi, rábano picante que suele acompañar al sushi, a la manera de comer sashimi o pescado crudo.

Hasta aquí hemos podido constatar que para lograr un alto crecimiento en las exportaciones agrícolas se necesita diversificar los productos y dinamizar la demanda de los consumidores. En la siguiente sección reflexionaremos sobre el caso de China, que en los últimos quince años aumentó notablemente sus exportaciones de hortalizas a Japón.

\section{El "gran auge" de las exportaciones hortofrutícolas chinas: un ejemplo para México}

La gráfica 6 muestra las importaciones japonesas de hortalizas frescas y refrigeradas de China. Es muy interesante establecer una comparación con las mexicanas. Hasta 1990 Japón importó más verduras de México que de China. Sin embargo, la importación de China aumentó vertiginosamente hasta llegar a 42,000 MDY en 2001, mientras que la de México se estancó. China incrementó su exportación hortícola catorce veces en poco más de diez años. Desde 2001 la cifra está estancada, pero aún así es la primera potencia exportadora de hortalizas con más de 38,000 MDY en 2004 (tabla 2).

Si desglosamos las cifras de 2004 (tabla 3), las exportaciones de China están sumamente diversificadas y balanceadas. Entre estos productos, la seta "matsutake" es una mercancía de lujo cuyo precio CIF por kilo es de alrededor de cinco mil yenes. La seta "shiitake" es para consumo diario y

\section{Gráfica 6}

Las importaciones de hortalizas frescas y refrigeradas: México y China

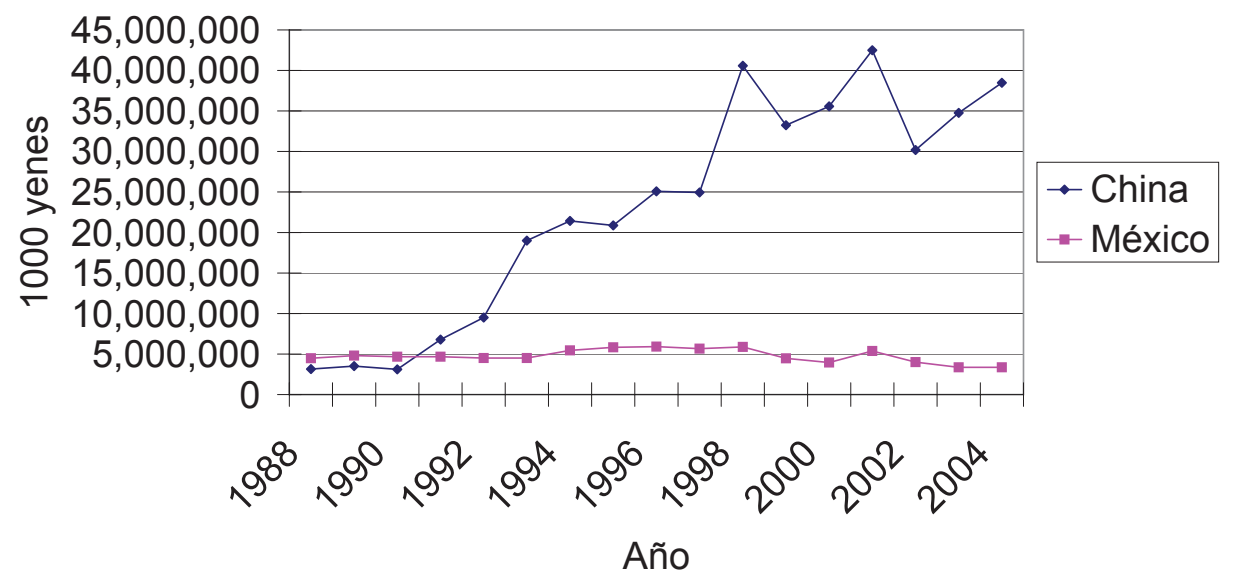


Tabla 2

La importación japonesa de hortalizas frescas y refrigeradas, 2004

\begin{tabular}{lcc}
\hline & $\begin{array}{c}\text { Valor } \\
\text { (millones de } \\
\text { yenes) }\end{array}$ & $\begin{array}{c}\text { Participación } \\
\text { (\%) }\end{array}$ \\
\hline China & 38,477 & 40.4 \\
Estados Unidos & 16,233 & 17.1 \\
Corea de Sur & 9,294 & 9.8 \\
Nueva Zelanda & 8,161 & 8.6 \\
Tailandia & 4,109 & 4.3 \\
Australia & 3,447 & 3.6 \\
México & 3,368 & 3.5 \\
Países Bajos & 2,412 & 2.5 \\
Taiwán & 1,960 & 2.1 \\
Canadá & 1,630 & 1.7 \\
\hline
\end{tabular}

Fuente: Ministerio de Finanzas de Japón.

nunca falta en la dieta japonesa. El poro —también llamado "porro" o "puerro"- es indispensable en la cocina japonesa.

\section{Tabla 3}

Las importaciones japonesas de hortalizas frescas y refrigeradas de China

\begin{tabular}{lc}
\hline Item & $\begin{array}{c}\text { Valor } \\
\text { (millones de yenes) }\end{array}$ \\
\hline Seta matsutake & 6,582 \\
Poro & 6,407 \\
Seta shiitake & 5,571 \\
Cebolla & 5,478 \\
Col & 2,345 \\
Bardana & 2,314 \\
Ajo & 2,282 \\
Legumbres & 2,110 \\
Zanahoria y nabo & 1,889 \\
Brócoli & 1,608 \\
Otros & 1,804 \\
Total & 38,477 \\
\hline
\end{tabular}

Fuente: Ministerio de Finanzas de Japón.

Veamos el comportamiento histórico del comercio de hortalizas entre Japón y China (gráfica 7). Según la gráfica 7, los productos están diversificados y el rubro de "otros" incluye muchos productos. Los japoneses nunca imaginaron que estos productos agrícolas, totalmente tradicionales, provinieran de algún país extranjero y sus importaciones desplazaran, aunque parcialmente, a la producción interna. En realidad, esta gran avalancha de productos agrícolas chinos, aunada a las importaciones masivas de bienes de consumo, y el traslado hacia China de los procesos industriales intensivos en mano de obra y recursos naturales y la consecuente pérdida de empleos, han provocado entre los japoneses un cierto sentimiento de estar expuestos a una amenaza china.

Una gran parte de las hortalizas chinas importadas por Japón son producidas por maquiladoras. Las empresas comercializadoras o distribuidoras japonesas introducen en China todos los insumos, semillas, fertilizantes, agroquímicos, técnicas para cultivar, empacar y procesar, producen hortalizas a bajo costo y aprovechan la mano de obra barata y disciplinada. Las distribuidoras japonesas y los supermercados empezaron a ofrecer verduras baratas a los consumidores. Los años noventa, en los que China incrementó masivamente sus exportaciones, coincidieron con la larga recesión de la economía japonesa. Como los salarios bajaron y la tasa de desempleo abierto subió, los comerciantes trataron de estimular la demanda con precios más bajos. "Destrucción de precios" era la frase de moda de la época. En este sentido, China siguió los pasos de México de hace algunos decenios en el sentido de que los distribuidores estadounidenses administraron varios tipos de agromaquilas y surtieron el mercado de verduras y frutas baratas (Gómez, 1990; González y Calleja, 1999).

Como mencionamos anteriormente, desde 2001 las importaciones japonesas 


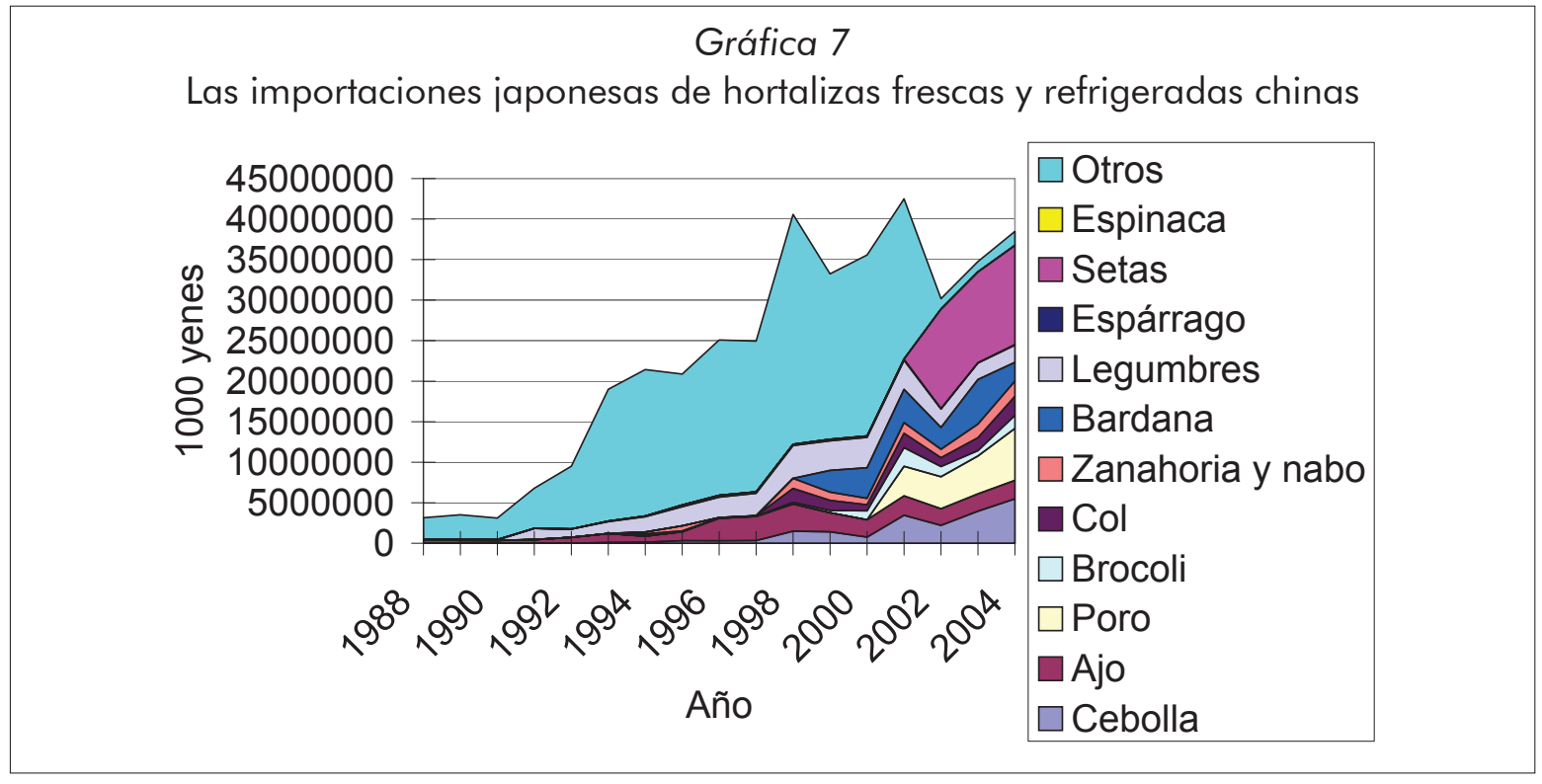

de hortalizas chinas comenzaron a estancarse. Una de las razones es que se detectó un agroquímico residual prohibido en la espinaca importada de China. Este hecho fue suficiente para suscitar entre los consumidores japoneses una gran sospecha sobre la calidad de los productos agrícolas chinos. $\mathrm{Al}$ disminuir los costos, los productos chinos perdieron la confianza de los consumidores nipones, quienes son muy sensibles a la calidad e inocuidad de los productos agrícolas y alimenticios. Dados los choques que provocaron los fenómenos de encefalopatía espongiforme bovina y los productos transgénicos, dicha tendencia no va a cambiar por lo menos a mediano plazo.

Las estadísticas de las importaciones de hortalizas frescas y refrigeradas señalan otro fenómeno interesante. La gráfica 8 muestra los precios CIF por kilogramo de hortalizas importadas de China y México. Los precios mexicanos prácticamente no cambiaron durante los últimos 15 años porque oscilaron alrededor de 150 yenes. Por su parte, los precios chinos muestran una tendencia contrastante: bajaron sistemáticamente desde 1992.
Varias hipótesis explican el comportamiento de los precios chinos. La primera es que cada año Japón importa más verduras "pesadas" y ha desplazado las hortalizas que tienen más valor por kilogramo. Según las estadísticas, en Japón la superficie cosechada y la producción de hortalizas "pesadas" como el nabo japonés, la bardana, la col, la col china y la sandía, entre otros productos, se redujo en los últimos años (tabla 4). Esto se debe al cambio demográfico entre los productores agrícolas (véase la siguiente sección) y a las características geográficas y demográficas de China. Dada la cercanía de China y su abundancia de gente joven y mano de obra barata, sus costos de producción y transporte son menores que el costo de producción en Japón.

Como se puede observar en la Tabla 5 , los precios de los productos principales bajaron de 1998 a 2005: la cebolla china pasó de 46 a 29 yenes; el ajo de 126 a 87 yenes; y la col de 56 a 36 yenes. La segunda hipótesis es que se han reducido los costos de transacción tales como los costos de transporte, de acopio, de almacenamiento y de seguros, entre otros. También debemos 


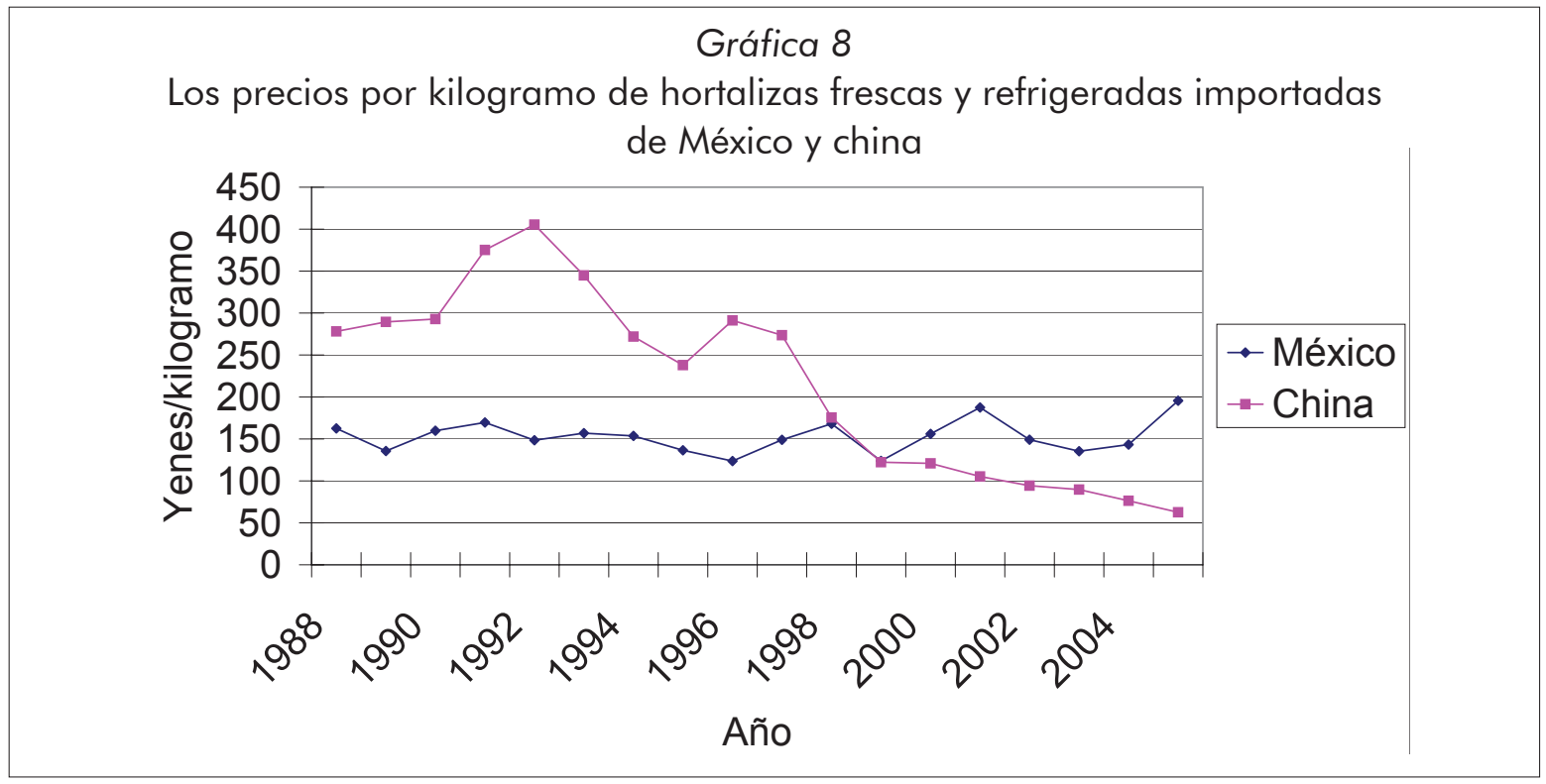

Tabla 4

La reducción de la producción de hortalizas "pesadas" en Japón

\begin{tabular}{lccrr}
\hline & \multicolumn{2}{c}{$\begin{array}{l}\text { Superficie } \\
\text { sembrada }\end{array}$} & \multicolumn{2}{c}{ Producción } \\
\hline & \multicolumn{2}{c}{$(1,000$ ha $)$} & \multicolumn{2}{c}{$(1,000$ ton $)$} \\
\hline Nabo japonés & 1990 & 2003 & 1990 & 2003 \\
Bardana & 15 & 42 & 2,336 & 1,752 \\
Col & 40 & 34 & 270 & 171 \\
Col chino & 29 & 21 & 1,220 & 1,376 \\
Sandía & 23 & 15 & 753 & 487 \\
\hline
\end{tabular}

Fuente: Anuario Estadístico de Japón, 2006.

agregar las economías de escala: el precio por unidad disminuye cuando el volumen de transacción aumenta.

Otras hipótesis pueden ser las siguientes: en primer lugar, es probable que los distribuidores japoneses presionen a los chinos para que bajen sus precios. Y en segundo lugar, la competencia entre productores podría ser rigurosa en China: con una población de más de 1,200 millones de personas e inmensas extensiones fértiles y aptas para la producción agrícola, los distribuidores japoneses podrían contar
Tabla 5

La reducción de precios por kilogramo de las hortalizas importadas de China

\begin{tabular}{lrrc}
\hline Ítem & \multicolumn{2}{c}{$\begin{array}{c}\text { Precio por kilo } \\
\text { (yenes) }\end{array}$} & Variación (\%) \\
\hline & 1998 & 2005 \\
\hline Cebolla & 45.96 & 29.01 & 36.9 \\
Ajo & 126.31 & 87.43 & 30.8 \\
Col & 55.54 & 36.21 & 34.8 \\
\hline
\end{tabular}

Fuente: cálculos del autor con información del Ministerio de Finanzas.

con numerosos lugares potenciales para la producción. A su vez, hay otros países asiáticos que están ansiosos por atraer inversiones, empleos y divisas. Esta competencia puede hacer que los productores bajen sus precios. De hecho, Japón firmó un acuerdo de asociación económica con Malasia y Filipinas, y está en proceso de negociación con Tailandia.

En la siguiente sección exploramos las posibilidades de México para diversificar su mercado y los negocios con Japón. 
Cómo penetrar en el cambiante mercado japonés: un reto para la agricultura mexicana

En los últimos dos decenios los japoneses han experimentado dos cambios demográficos alarmantes: el rápido envejecimiento de la población y una nueva estratificación socioeconómica. Estos procesos producen efectos positivos y negativos tanto en productores como en consumidores.

Como se observa en la gráfica 9 , la proporción de los habitantes de 65 años de edad o más fue del 7\% en 1970. Este porcentaje creció vertiginosamente y se estima que alcanzará el $26 \%$ en 2015, 29\% en 2025 y más del 35\% en 2050. Económicamente, esto significa que cada año en Japón habrá más propensión al consumo. Además, la reducción de la población económicamente activa afectará al nivel de producción. De hecho, este fenómeno lo ha resentido el sector agrícola. Según las estadísticas recientes, el número de "agricultores comerciales" - los que tienen ventas superiores a 500,000 yenes- disminuyó de 2'337,000 a 1'949,000 entre 2000 y 2005 , es decir, una reducción del 16.6\% en tan solo 5 años (Yomiuri Shimbun, 2005).

Tras su derrota en la II Guerra Mundial, las fuerzas militares obligaron al país a aplicar un proceso drástico de igualación socioeconómica a través, por ejemplo, de una total reforma agraria y la disolución de los grandes conglomerados conocidos como "zaibatsu", entre otras. Los estadounidenses pensaron que la desigualdad era la causa principal de la militarización del país. Con dichas medidas Japón pudo tener una sociedad sumamente igualitaria, pero la situación cambió en los últimos años como se observa en el coeficiente de Gini (gráfica 10). Algunos investigadores han afirmado que en Japón se observa una reproducción de la desigualdad (Sato, 2000; Tachibanaki, 2004) que algunos llaman "la latinoamericanización de Japón”, expresión basada en una visión estereotipada de Latinoamérica.

Por sí sola esta estratificación socioeconómica es un gran problema para la sociedad japonesa. Los japoneses afrontaron el gran reto de contrarrestar de alguna manera esta tendencia y la desestabi-

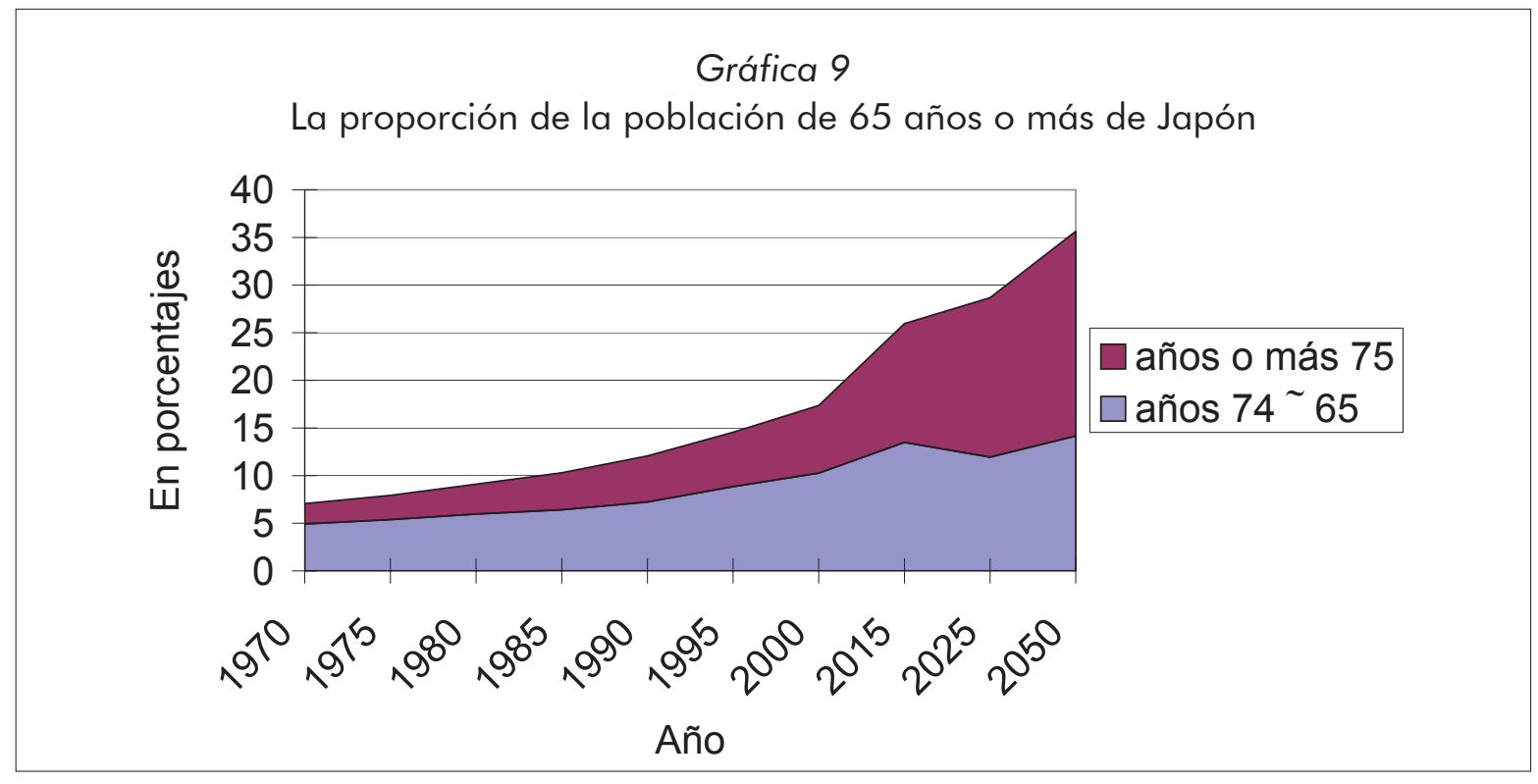




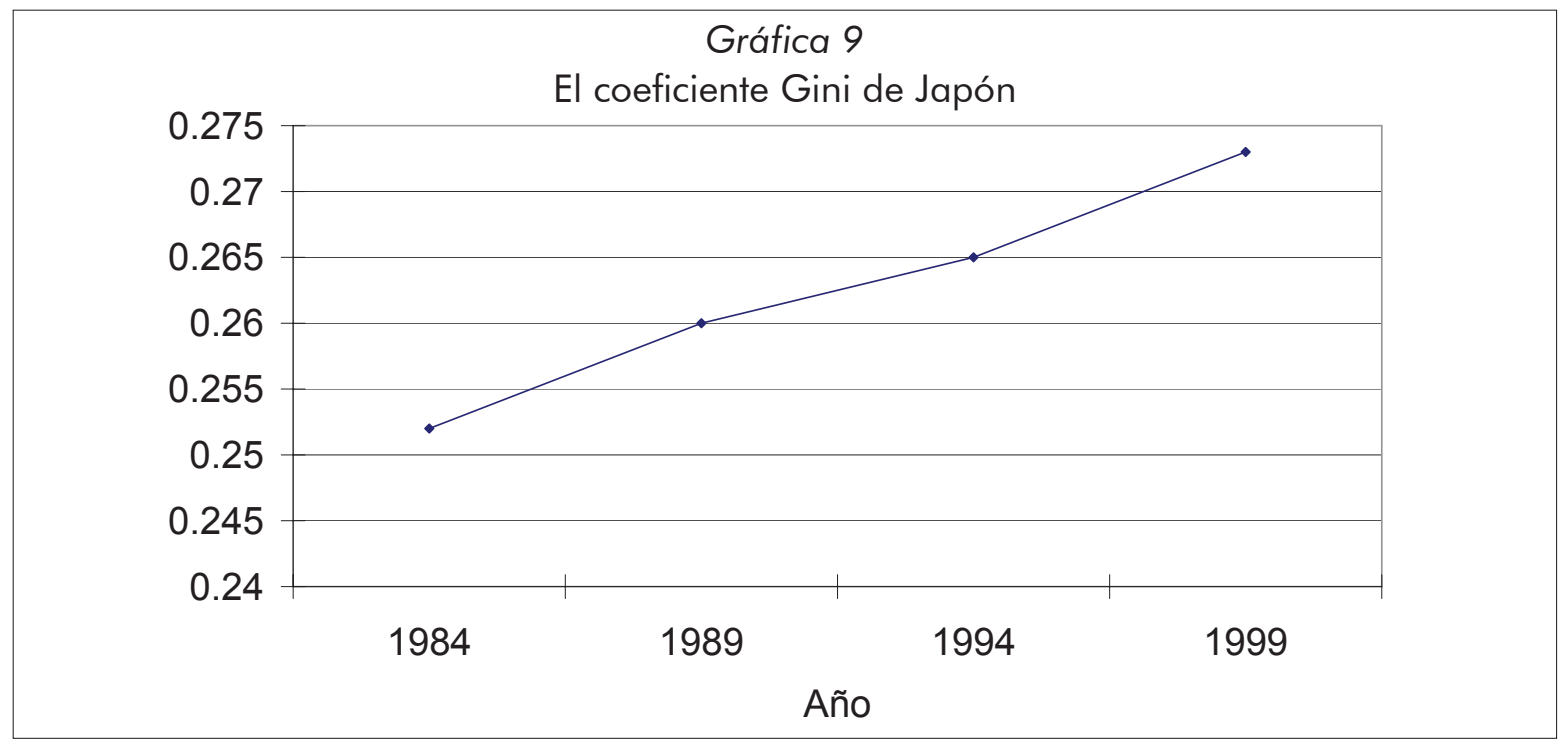

lización social que puede provocar. Sin embargo, esta tendencia es muy fuerte y ya se vislumbra un proceso de polarización del mercado de consumo. En cuanto al mercado alimentario, hay consumidores que demandan productos baratos: la calidad no les importa tanto, pero en el otro extremo hay consumidores que están dispuestos a pagar un mayor precio por las mercancías de buena calidad, buena fama y buen gusto: las verduras, granos y sus derivados cultivados orgánicamente con menos agroquímicos y libres de transgénicos, por ejemplo. Hace algunos años se fundaron unas cadenas de supermercados "de lujo", que se especializan en productos alimenticios importados y locales. Venden buenos vinos de todo el mundo, quesos de todas las variedades, todo tipo de frutas tropicales, incluso aguacates, limones y mangos de México colocados en los anaqueles como joyas. En otros anaqueles cercanos exhiben verduras cosechadas esa misma mañana con una etiqueta que muestra el nombre y la foto del productor.

En Japón los supermercados no pueden vender verduras sin indicar el país o provincia de origen. El Ministerio de Agricul- tura empezó a sugerir a los restaurantes que señalaran así mismo el origen de sus ingredientes. Esta política es una nueva medida proteccionista que tal vez, bajo el pretexto de proteger al consumidor, esconda dicha intención. Sin embargo, puede ser una gran oportunidad para diferenciar los productos mexicanos. Afortunadamente, los consumidores japoneses no tienen mala imagen de México, tal vez porque los productos mexicanos no tienen mucha presencia en el país.

A fin de que México gane presencia en el mercado japonés, puede seguir la estrategia que exponemos a continuación.

1. Promover la "buena calidad" más que el "buen precio", porque en Japón hay consumidores muy exigentes con la calidad de productos a cualquier precio.

2. Promover la venta de "alimentos inocuos y saludables". México ya ha empezado a exportar productos orgánicos a Estados Unidos, a varios países europeos e incluso a Japón. En esta área, el obstáculo está en el mercado interno (Gómez, Gómez y Schwentesius, 2003). La mayoría de los consumidores mexicanos no valoran la bondad de estos productos y 
no están dispuestos a pagar precios más altos. Es importante entonces educar a los consumidores nacionales, pero esto será un reto de largo plazo.

3. Estrenar un "brand name". En esta área varios países latinoamericanos han sido pioneros en Japón. La Federación Nacional de Cafeteros de Colombia firmó un contrato con una compañía ferroviaria de Japón —una de las compañías privatizadas en 1987- para poner cafeterías con su logotipo en algunas estaciones de Tokio. El café que se vende en el tren bala (Shinkansen) se sirve en vasos desechables con el logotipo de "Café de Colombia", la misma estrategia que siguió Starbucks en los aviones de United Airlines.

En octubre de 2004 la federación colombiana realizó una campaña de "Café de Colombia" en un partido de la liga japonesa de fútbol. Organizó una modesta exhibición de sus productos a un lado del estadio, donde una señorita colombiana ataviada con el traje típico de Colombia repartió folletos de su café, y después del partido regaló una lata de café con su marca a los aficionados que salían del estadio (Yokohama Fc, 2006). La campaña tenía la intención de que asociaran el dinamismo del fútbol y la afición del equipo favorito al nombre de Colombia. Para los aficionados Colombia se convirtió en el país del café y del fútbol.

Veamos a continuación el ejemplo de Chile. A finales de los años noventa se realizó una campaña de promoción de vinos chilenos en Japón. Un organismo paraes- tatal chileno emitió varios comerciales televisivos. Aunque la imagen que aparecía en estos comerciales era de las Cataratas de Iguazú, que no tenía nada que ver con Chile, fue muy impresionante para los consumidores que no conocían Sudamérica. Al final del comercial se decía que cada botella de vino chileno contenía una tarjeta para participar en el sorteo de un viaje a Chile. Tras unos cuantos años, los vinos chilenos, al principio conocidos por su excelente "cost performance", ganaron terreno.

Para alcanzar la meta de diversificar las exportaciones, los mexicanos tienen que acercarse a los consumidores japoneses, sin esperar que sean los comerciantes japoneses quienes vengan a comprarles sus productos. Será indispensable la colaboración entre empresarios, gobiernos y académicos para profundizar más en el conocimiento de la cultura japonesa.

Los empresarios necesitan invertir más para adquirir información de primera mano sobre el país: enviar a sus empleados y/o agentes a Japón para conocer las necesidades y peculiaridades de su mercado. La Foodex Japan, una de las ferias internacionales de alimentos y bebidas más importantes del mundo, que anualmente se celebra en Japón, ${ }^{5}$ es una muy buena ocasión para encontrar nuevos clientes.

El gobierno federal, por ejemplo, la Secretaría de Relaciones Exteriores (SRE), a través de su cuerpo diplomático en Japón, puede contribuir con datos e información. La oficina del Banco Nacional de Comercio Exterior (Bancomext) en Tokio tiene también muchos contactos en Japón. El 
Consejo Nacional de Ciencia y Tecnología (Conacyt) y la Agencia Japonesa para la Cooperación Internacional (JICA) otorgan becas para estudiar en Japón. Por último, los gobiernos estatales pueden apoyar a los empresarios locales cuando deseen investigar más profundamente sobre el mercado japonés.

Asimismo, los investigadores universitarios pueden participar con muchas publicaciones sobre Japón. Las contribuciones no deberían limitarse al plano académico, sino que también los estudiantes universitarios pueden hacer algo al invertir sus recursos y tiempo en los estudios sobre Japón. Para ello es indispensable aprender el idioma, inversión de largo plazo pero indispensable.

La diversificación de productos y mercados entre México y Japón tiene innumerables beneficios. Los consumidores japoneses disfrutarán de más variedades de verduras y frutas de alta calidad, y los productores mexicanos ganarán más sin exponerse a una rigurosa competencia de precios. ח19

\section{Apéndice: las fuentes de datos estadísticos}

Los datos estadísticos utilizados en este artículo son, en su mayor parte, los que publica el Ministerio de Finanzas de Japón en su página Web de las Aduanas: http://www.customs.go.jp/toukei/srch/indexe. htm. Las cifras están en yenes.

La gráfica 1 fue elaborada con datos de la Organización de Agricultura y Alimentación de las Naciones Unidas, disponibles en http://faostat.fao. org/. Los datos de la gráfica 9 fueron tomados de la página del Instituto Nacional de Investigación de Población y Seguridad Social disponible en http:// www.ipss.go.jp/index-e.html. La gráfica 10 se basa en los datos compilados por el Buró de Estadísticas tomados de http://www.stat.go.jp/data/zensho/topics/1999-1.htm. Estas cifras están modificadas con el objeto de hacer una comparación internacional, por lo cual no coinciden con las cifras publicadas en National Survey of Family Income and Expenditure disponible en http://www.stat.go.jp/english/index. htm. El Anuario Estadístico de Japón, la fuente de los datos de la tabla 4, también se puede conseguir en la misma página. Las cifras de la tabla 1, por otra parte, se tomaron de la página del Ministerio de Agricultura, Silvicultura y Pesca, disponible en http://www.toukei.maff.go.jp/world/index.files/ wagakunijisseki.htm.

\section{Notas}

1 La información está disponible en http://www. customs.go.jp/toukei/srch/indexe.htm.

2 El producto interno bruto (PIB) de Japón en 2004 fue de 4'623,398 millones de dólares, mientras que el de América Latina y el Caribe fue de 2’018,715, según datos del Banco Mundial.

3 Un yen equivale aproximadamente a 10 centavos de peso mexicano.

4 El "prince melon" es una variedad cruzada del melón de origen sudeuropeo con el melón nativo de Japón (“makuwa-uri”). Fue bautizado con este nombre inglés en Japón.

5 Véase la página electrónica de la feria en http:// www.jma.or.jp/foodex/.

\section{Referencias bibliográficas}

Gómez, M. y F. Caraveo (1990), "La agromaquila hortícola: nueva forma de penetración de las transnacionales", en Comercio Exterior (México), vol. 40, núm. 12, pp. 1193-1199.

Gómez, M., L. Gómez y R. Schwentesius (2003), “La agricultura orgánica: una alternativa tecnológica sustentable para México", en J. Solleiro y M. del Valle (ed.), Estrategias competitivas de la industria alimentaria, Plaza y Valdés, México, DF, pp. 257-278.

González, H. y M. Calleja (1999), "La construcción de cadenas internacionales de frutas y hortalizas: vínculos e interdependencia entre Texas y México", en H. Carton et al. (coord.), Agricultura de exportación en tiempos de globalización. El caso de hortalizas, frutas y flores, Juan Pablo Editores, México, DF, pp. 23-68.

Sato, T. (2000), Fubyôdô shakai, Nippon (Japón: una sociedad desigual), Chûô Kôron Shin Sha, Tokio.

Tachibanaki, T. (ed.) (2004), Fûin sareru fubyôdô (La desigualdad sellada), Tôyô Keizai Shimpô Sha, Tokio.

Yokohama FC (2006), disponible en http://www. yokohamafc.com/, consultado el 22 de febrero de 2006.

Yomiuri Shimbun (diario japonés), 21 de septiembre de 2005.

MÉXICO YLACUENCADEL PACÍFICO vol. 8, núm. 26 / septiembre-diciembre de 2005 